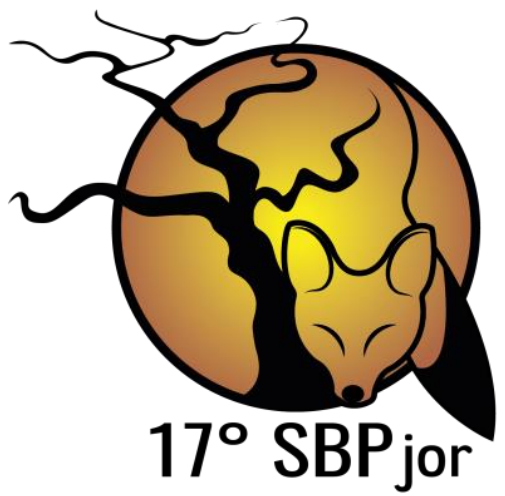

\title{
A Tensão Comunicacional do Jornalismo: um olhar por sobre a enunciação positiva
}

\author{
Guilherme Lucian ${ }^{1}$ \\ Ângela Teixeira de Moraes $^{2}$ \\ Universidade Federal De Goiás
}

Resumo: Neste trabalho trataremos da busca de um sentido ético à comunicação - articulando-a a uma base existencial de vinculação pressuposta na enunciação construtiva do jornalismo. Também perscrutaremos, por tessituras discursivas, a tensão entre disposição instrumental e entendimento comunicativo, para daí pôr em relevo as trilhas normativas a uma episteme que emerge quando partilhadas experiências de afetividade. E por fim discutiremos em que medida o exercício jornalístico, ao operar por "silêncios", deixa-se guiar por horizontes de justiça no plano da cidadania. Espera-se, com isso, tangenciar outras tendências epistemológicas ao estudo dessa área.

Palavras-chave: comunicação; discurso; normatividade; silêncio; epistemologia.

\footnotetext{
${ }^{1}$ Doutorando do Curso de Comunicação da Faculdade de Informação e Comunicação da Universidade Federal de Goiás; e-mail: guilherme.lucian@gmail.com

${ }^{2}$ Orientadora do trabalho. Professora Doutora do Programa de Pós-Graduação em Comunicação da UFG. E-mail: prof.atmoraes@gmail.com
} 


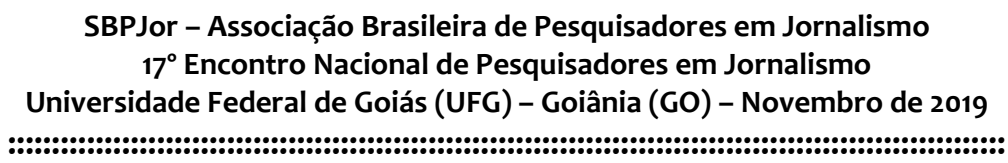

\section{A NATUREZA ÉTICA DA ENUNCIAÇÃO JORNALÍSTICA}

Há uma tensão na configuração do jornalismo, a qual emerge quando são postas numa tessitura coerente as conversas sociais de uma época. Essa tensão é de ordem comunicacional, na medida em que, à trajetória de sua enunciação, variam sem rumos bem delineados a lógica meramente transmissiva dos eventos narrados e o esforço discursivo de abertura às realidades do cidadão. Tensionam-se, pois, disposição instrumental e entendimento comunicativo ${ }^{3}$.

O exercício jornalístico é historicamente situado na urgência de organização do que há de mais aleatório, disperso e imprevisível numa realidade social, sendo-lhe próprio um tipo singular de narrativa, qual seja: a da relevância atribuída segundo os termos de um quadro de referência familiar - o qual, erguido sobre fundamentos duma pretensa objetividade assumida, põe em circulação simbólica os sentidos que configuram nosso tempo. Há, contudo, variáveis aí pressupostas, sobretudo quando se alteram nortes aos quais tendem a enunciação. O caráter objetivo, conforme o contexto, cede vez a outras racionalidades (não menos inteligíveis, nem mais sistemáticas); estas que, de modo geral, circunscrevem o jornalismo num horizonte ${ }^{4}$ que coordena sensibilidades

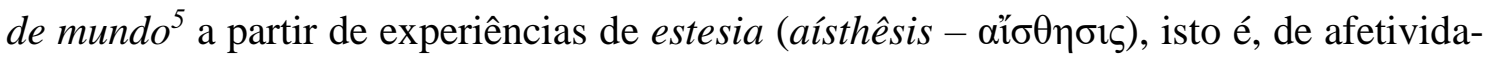
des [com]partilhadas.

É nesse sentido que despontou à luz nos últimos anos um tipo singular de jornalismo, cuja trajetória discursiva firmou na história a urgência da alteridade na própria tessitura de sua enunciação. Dá-se a este exercício o termo positivo ${ }^{6}$ (ou construtivo,

\footnotetext{
${ }^{3}$ Tal qual em Habermas (2012), por exemplo, quem antes analisou a tensão entre as razões comunicativa (que opera segundo pretensões de verdade, retidão, confiança e inteligibilidade) e teleológica (orientada por um propósito qualquer, o qual passa ao largo do entendimento mútuo).

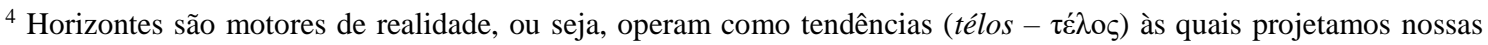
ações. Ocorre que, nesta condição mesma, serão sempre pontos distantes em comum; porém necessários à coesão dos propósitos.

${ }^{5}$ Essa propositura hipotética é provisória, devendo, portanto, ser aqui considerada com as devidas ressalvas conceituais.

${ }^{6}$ Para citar exemplos desse tipo de exercício jornalístico, destacam-se os portais brasileiros "Só Notícia Boa" e "Jornal de Boas Notícias"; norte-americanos como "Positive.News", "Daily Good" e "Good News Network"; os diários franceses "Bonnes Nouvelles", "Bonnes Nouvelles du Jour !" e "Le Journal de Bonnes Nouvelles"; ou ainda periódicos italianos como "BuoneNotizie" e L'Altraitalia".
} 


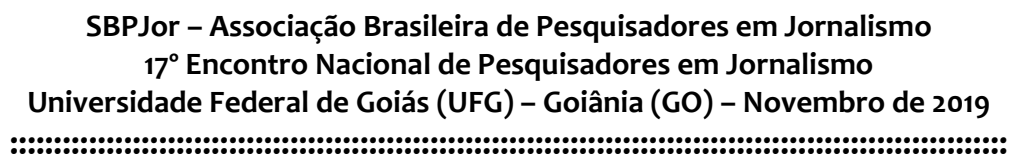

conforme o vocabulário adotado ${ }^{7}$ ), especialmente por solicitar do público - a partir de intervenções cognitivas com fins a comportamentos solidários - uma mudança de atitude em relação ao mundo. Este ensaio, portanto, é demarcado pelo interesse de examinar a dimensão comunicativa na interface entre jornalismo e cidadania, com o propósito de realçar algumas questões teóricas emergentes de uma pesquisa em desenvolvimento. Busca-se no tensionamento entre a comunicabilidade da enunciação positiva e a incomunicabilidade do sistema de narrativa referencial, enfim, uma centralidade comunicacional à compreensão dos processos sociais contemporâneos.

Sendo assim, explicita-se o dispositivo teórico-analítico nos seguintes termos: até que ponto o sistema midiático - aqui circunscrito segundo as condições enunciativas positivas do jornalismo - expressa uma noção de comunicação que pode ao fim ser universalizada ${ }^{8}$ ? Para traçar outras rotas à cidadania, pois, pretende-se questionar: qual a condição comunicacional que emerge da tensão entre positividade e referencialidade ${ }^{9}$ jornalísticas?

Considera-se "comunicação", segundo os limites pontuais deste ensaio, o processo de troca e circulação de sentidos que ao fim assegura um vínculo humano ${ }^{10}$; devidamente firmado num horizonte normativo ${ }^{11}$ de justiça. E "cidadania", pois, a condição existencial pela qual, nesse mesmo horizonte, somos convocados à manutenção responsável dos laços sociais. Eis porque aqui se enovelam tais noções, sem pretensão de esgotá-las no eixo epistemológico proposto.

\footnotetext{
${ }^{7}$ Não há consenso (nem dissenso suficiente) em relação às diferenças conceituais entre tais termos, porque parecem ambos sugerir uma responsabilidade sensível que é primado à ação discursiva do jornalismo. $\mathrm{O}$ enunciado positivo aponta para uma mudança de atitude no mundo - conforme são questionados os parâmetros tipificáveis da notícia -, enquanto que o construtivo toma o futuro por horizonte normativo, tendo-o então como um norte possível e sempre às vistas da democracia.

${ }^{8}$ Não porque absoluta ou totalizante, mas por tornar-se válida àqueles que se debruçam sobre tal questão.

${ }^{9}$ Vista aqui, segundo parâmetros discursivos, como a enunciação legítima e historicamente situada em relação ao que é por vezes violento e desolador no exercício de enunciação jornalística.

${ }^{10}$ Para estudo aprofundado, cf. BRAGA (2008; 2011; 2016), SIGNATES (2012a; 2012b), SODRÉ (2006; 2014) e WOLTON (1997; 2006).

${ }^{11}$ Normativo diz respeito à "atitude intelectual de considerar as coisas a partir do modo como elas devem ser essencialmente" (GOMES, 2008, p. 110), configurando-se, portanto, como a busca de um ideal possível. A este respeito, cf. GOMES, W. Esfera pública política e comunicação em direito e democracia de Jürgen Habermas. In: __, W.; MAIA, R. C. M. Comunicação e democracia: problemas e perspectivas. São Paulo: Paulus, 2008. Cap. 2, p. 69-115.
} 


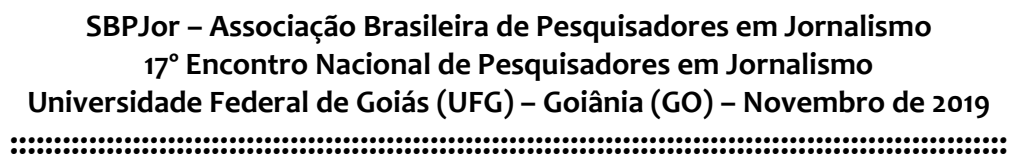

Partamos então às reflexões. Movimentos de autocrítica permeiam desde há muito a atividade jornalística - os quais, de modo geral, voltam-se aos (re)arranjos de sua deontologia. A tensão, afinal, situa-se em relação às pressões exercidas por tendências mercadológicas e as propostas de conectar a enunciação noticiosa à vida cívica (CORREIA, 2010, p. 71). É nesse ponto que a discursividade do jornalismo, especialmente aquela que tangencia a dimensão positiva, pode operar como uma experiência midiática comunicativa, na medida em que o horizonte de retidão aí pressuposto norteia ao fim uma pretensão de validade específica, qual seja: a do afeto ${ }^{12}$.

Isso não significa, porém, inferir que a enunciação de referência opere tão somente nos termos da violência e da não-solidariedade em relação às vivências do Outro, porque há em sua discursividade uma legitimação ancorada no compromisso ético com os cidadãos. Ocorre que, por situar-se segundo os interesses de uma empresa privada os quais nem sempre em consonância com o que há de socialmente útil no ato mesmo de organizar a realidade -, seu discurso normativo é por vezes confrontado com imperativos do mercado (MORAES, 2014). Essa tensão demarca, pois, um novo curso à trajetória enunciativa do jornalismo: a da busca por sentidos alternativos.

O discurso do jornalismo de referência é fundado nos processos de institucionalização sistêmica - na medida em que, por linguagens distintivas, delineiam-se trajetos a partir de interesses que lhe são próprios -, os quais nem sempre operam como mediadores dos diálogos sociais. É nesse ponto que seu propósito informativo assume uma disposição instrumental, em cuja tessitura é inscrito o tensionamento entre o ato de narrar realidades e a atribuição de sentidos a serem circulados. Noutros termos, informar

e dar sentido não implicam as mesmas obrigações morais. Ambas as ações derivam de tipos muito diferentes de ética. A informação comanda uma ética deontológica, isto é, centrada no dever de relatar. À atribuição de sentido, é bastante congruente uma ética teleológica, isto é, relativa aos propósitos da informação (GAUTHIER, 2010, p. 266) ${ }^{13}$,

\footnotetext{
${ }^{12}$ Isto é, uma predisposição senciente às realidades alheias; ou, noutros termos, um esforço único (sem recatos ou branduras) de emprestar-se segundo os termos de uma clareza sensível à existência do Outro.

13 Tradução livre a partir do original em francês: “Informer et donner du sens n'entraînent pas les mêmes obligations morales. Des deux actions découlent même des types d'éthique bien distincts. L'information commande une éthique déontologique, c'est-à-dire centrée sur le devoir de rapporter. À l'attribution de sens, est plutôt congruente une éthique téléologique, c'est-à-dire relative aux finalités de l'information".
} 
SBPJor - Associação Brasileira de Pesquisadores em Jornalismo

$17^{\circ}$ Encontro Nacional de Pesquisadores em Jornalismo

Universidade Federal de Goiás (UFG) - Goiânia (GO) - Novembro de 2019

o que solicita do jornalista - ao trazer à luz jornadas sociais - uma responsabilidade (e sensibilidade equivalente) em relação às trajetórias históricas da ação enunciativa. Sendo assim, confrontam-se duas atitudes frente à tarefa de atribuir coerência ao mundo: pôr em relevo o que é acontecimento e dar a isto um propósito; circunscrevê-lo, pois, num horizonte que contemple a dimensão humana dos relatos de realidade. Em ambas, porém, preserva-se na enunciação um conjunto de combinações deontológicas com fins à redução da realidade por recortes espaço-temporais (FRANCISCATO, 2014, p. 87) ${ }^{14}$, os quais ao fim configuram o que é noticiável. Eis porque, ao lançar-se no mundo para (re)construí-lo discursivamente segundo o alcance de sua urdidura, o jornalismo singulariza os princípios norteadores que lhe permitem falar a respeito do real, situando-se assim entre o compromisso ético de organizar o que se vê aí disperso e a urgência quanto a mobilizar sentidos que façam pontes aos saberes e vivências de uma época.

Reflitemos, então. Convencionou-se chamar de notícia o tipo de acontecimento social que, ao manifestar-se a partir de parâmetros de relevância tipificáveis (GUERRA, 2014$, p. 41$)^{15}$ - isto é, segundo o aporte de valorações próprias à atividade de organização da realidade -, é devidamente expresso na enunciação ${ }^{16}$. Há nisto uma lógica transmissiva (sobretudo no que concerne à mecânica das escolhas arbitrárias do que será ao fim evidenciado de cada evento); mas há aí pressuposta, em contrapartida, uma dimensão comunicativa que por vezes escapa aos contornos do horizonte ético posto às vistas da atividade jornalística, a qual opera como ação transformadora desta mesma realidade. $\mathrm{O}$ ato de informar, pois, torna-se condição a novas formas de conscientização e mobili-

\footnotetext{
${ }^{14}$ Cf. FRANCISCATO, C. E. Limites teóricos e metodológicos nos estudos sobre a noticiabilidade. In: SILVA, G.; SILVA, M. P. D.; FERNANDES, M. L. Critérios de noticiabilidade: problemas conceituais e aplicações. Florianópolis: Insular, 2014. Cap. 5, p. 85-113.

15 Cf. GUERRA, J. L. Uma discussão sobre o conceito de valor-notícia. In: SILVA, G.; SILVA, M. P. D.; FERNANDES, M. L. Critérios de noticiabilidade: problemas conceituais e aplicações. Florianópolis: Insular, 2014. Cap. 2, p. 39-49.

${ }^{16}$ Esta que, por atender aos propósitos diversos de uma instituição - porquanto é como comumente se legitima o ato mesmo de narrar a realidade -, pode então passar ao largo das urgências sociais de uma época.
} 
SBPJor - Associação Brasileira de Pesquisadores em Jornalismo

$17^{\circ}$ Encontro Nacional de Pesquisadores em Jornalismo

Universidade Federal de Goiás (UFG) - Goiânia (GO) - Novembro de 2019

zação sociais; espécie de força para o bem $^{17}$ que circunscreve na história suas normatividades discursivas.

Sendo assim, pressupõe-se na cena enunciativa da positividade um tipo singular de valor-notícia-serviço (SILVA, 2016, p. 55) $)^{18}$ - o qual, tão logo instituído pelo primado da comunicação, também opera como pretensão de validade que à superfície traz um novo fato discursivo; ou, noutros termos, o que se pretende dizer há ao fim de ser válido a todos para então compor no plano da cidadania um senso de retidão e de comunidade. A negatividade é também legitimada, sim, embora comumente expressa segundo a lógica do desamparo e da "violência tecnocrática no seio de práticas profissionais antiéticas" (MEDEIROS, 2016, p. 226) ${ }^{19}$. Eis como, afinal, é justa a enunciação que solicita o público a atuar como participante num contexto dialógico racional (e senciente).

Lidamos com uma enunciação agatológica, portanto, a qual se ampara na noção de "bem comum" para firmar no tecido social um novo topos à discursividade jornalística, isto é, um lugar comum enunciativo em que, uma vez construídas as regras do jogo na ocorrência histórica do próprio dizer, universalizam-se saberes válidos e solidariedades $^{20}$. Rompe-se com a ordem discursiva do jornalismo - cujos critérios à visibilidade do acontecimento passam por vezes ao largo do que não é violento -, à medida que, pela palavra em ato, cria-se um novo gênero ${ }^{21}$ norteador. Por tratar-se então duma forma simbólica inédita, a positividade carece doutra linguagem distintiva, conforme são produzidos sentidos a partir do que se diz.

\footnotetext{
${ }^{17}$ Visto aqui como uma disposição natural e sensível ao que é posto como Bem (agathós - ảy $\alpha \theta$ ó $)$; validado discursivamente na busca por um sentido pleno às coisas.

${ }^{18}$ Cf. SILVA, G. Para pensar critérios de noticiabilidade. In: SILVA, G.; SILVA, M. P. D.; FERNANDES, M. L. Critérios de noticiabilidade: problemas conceituais e aplicações. Florianópolis: Insular, 2014. Cap. 3, p. 51-69.

${ }^{19}$ Cf. MEDEIROS, M. Cidadania, direitos humanos e jornalismo: percalços históricos e violência institucionalizada. In: SIGNATES, L.; MORAES, Â. Cidadania comunicacional: teoria, epistemologia e pesquisa. Goiânia: Gráfica UFG, 2016. Cap. 9, p. 213-228.

${ }^{20}$ Estas que, ao fim, manifestam-se como "relações interpessoais ordenadas de modo legítimo" (HABERMAS, 1998, p. 315). Cf., também, HABERMAS, 1999; 2012.

${ }^{21}$ Logo, "um tipo de prática social discursiva" (VAN DIJK, 2008), definida por estruturas discursivas e contextuais (p. 141).
} 


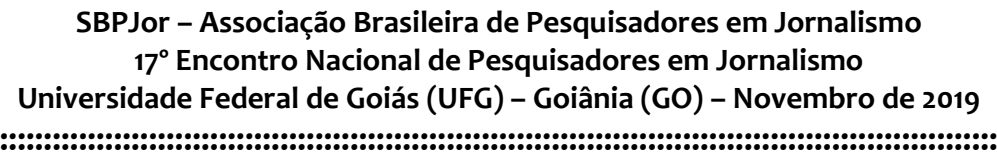

Ao tornar-se válido segundo as condições de existência da formação discursiva ${ }^{22}$ que lhe é própria, o saber positivo passa a operar como uma singularidade expressa na enunciação jornalística; máquina discursiva, portanto (liberada ao conhecimento) - a qual, como episteme às novas falas de uma época, constitui-se noutras ressonâncias. Por isso supor que

há, muito regularmente nas sociedades, uma espécie de desnivelamento entre os discursos: os discursos que 'são ditos' no correr dos dias e das trocas, e que passam com o ato mesmo que os pronunciou; e os discursos que estão na origem de certo número de novos atos de fala que os retomam, transformamnos ou falam deles, portanto, os discursos que, indefinidamente, para além da sua formulação, são ditos, permanecem ditos e estão ainda por se dizer $^{23}$ (FOUCAULT, 2001, p. 21-22),

os quais ao fim - ao menos no que pese trazer à superfície o "bem" pressuposto no ato mesmo de enunciar - emergem de valorações sistemáticas, isto é, a partir de parâmetros firmados na tessitura do próprio discurso. À formação discursiva da positividade, pois, traça-se uma trajetória ilocucionária, já que aí operam disposições para ouvir e compreender. Eis porque, mesmo em conformidade com outras urgências (sobretudo comerciais), mantém-se na enunciação jornalística sua constituição heterogênea. Renovam-se assim, por um sem-número de ramificações na discursividade mediada do jornalismo, as experiências e sensibilidades de uma época.

Pressupõe-se então outra postura ao jornalista; cabe-lhe a tarefa, para além de analisar jornadas, o compromisso de deitar um olhar senciente ${ }^{24}$ à realidade - não necessariamente conduzido segundo as tipificações da notícia -, e falar, pois, a partir do discurso do Outro; ter-lhe estima na consistência ressonante da enunciação, à medida que, dum mesmo horizonte de retidão, surja-lhe na voz a tessitura [com]partilhada da

\footnotetext{
${ }^{22}$ Isto é, "um conjunto de regras anônimas e históricas que definem para uma área social as condições de exercício de uma função enunciativa" (MORAES, 2014, p. 02).

${ }^{23}$ No original: "il y a, très régulièrement dans les sociétés, une sorte de dénivellation entre les discours : les discours qui «se disent » au fil des jours et des échanges, et qui passent avec l'acte même qui les a prononcés; et les discours qui sont à l'origine d'un certain nombre d'actes nouveaux de paroles qui les reprennent, les transforment ou parlent d'eux, bref, les discours qui, indéfiniment, par-delà leur formulation, sont dits, restent dits, et sont encore à dire".

${ }^{24} \mathrm{Ou}$ seja, uma habilidade consciente de notar (para então permitir-se) o que por vezes escapa às fronteiras da própria vivência; passar então de uma percepção natural fundada no egocentro à atitude ética que contemple o sociocentro. Para tal questão, cf. SILVA, L. M. D. Informação e mudança: repensando o conceito de comunicação e de processos na comunicação social. In: SIGNATES, L.; MORAES, Â. Cidadania comunicacional: teoria, epistemologia e pesquisa. Goiânia: Gráfica UFG, 2016. Cap. 2, p. 37-65.
} 
SBPJor - Associação Brasileira de Pesquisadores em Jornalismo

$17^{\circ}$ Encontro Nacional de Pesquisadores em Jornalismo

Universidade Federal de Goiás (UFG) - Goiânia (GO) - Novembro de 2019

alteridade. Tensionar, afinal, o contato entre esta razão sensível ${ }^{25}$ e os valores construídos no plano da cidadania; eis como, do mero ato de informar, passaria o jornalismo à ação de firmar pontes comunicantes entre universos simbólicos tão diferentes.

\section{DA TENSÃO AO SILENCIAMENTO}

Até aqui, tratamos de observar as condições de possibilidade à formação discursiva de atos de fala sencientes, os quais, em jogos de vinculação, tangenciam um tipo particular de enunciação jornalística, qual seja: o da positividade que assegura, por meio de ingerências cognitivas ${ }^{26}$, novas situações afetivas e linguageiras. Resta então questionar se na tensão entre razão sensível - assumida como fundamento à comunicação - e imperativo instrumental é possível tender para um ideal normativo quando os contextos do jornalismo parecem sugerir um trajeto contrário ao entendimento.

Mudam-se as experiências de cidadania, afinal - à medida que em novas tessituras discursivas são construídas relações de valores partilhadas. Situações comunicativas dessa ordem, porém, demandam interferências na existência do Outro, porque há em cada troca uma perda simbólica significativa. Por isso uma enunciação tem por dever marcar (para então assegurar) como válida a intersubjetividade expressa no ato mesmo de tecer conversas sociais, uma vez que é

pela partilha de um só e mesmo conjunto de discursos que indivíduos, tão numerosos quanto se queira imaginar, definem sua pertença recíproca. Aparentemente, a única condição requerida é o reconhecimento das mesmas verdades e a aceitação de certa regra - mais ou menos flexível - de conformidade com os discursos validados ${ }^{27}$ (FOUCAULT, 2001, p. 45),

\footnotetext{
${ }^{25} \mathrm{Ou}$, tal qual exposto neste ensaio, uma sensibilidade de mundo que é primado à ação; fundada em princípios agatológicos, os quais orientam a enunciação. Esta premissa, carece aqui costurar, será melhor perscrutada em futuros trabalhos.

${ }^{26}$ Tais como fazer ver os hiatos que nos separam do Outro; [re]arranjar discursos que antes se situaram em torno do que é violento e degradante; solicitar, pela linguagem, afetividades inéditas; sustentar como ideais outras normatividades num horizonte de justiça possível.

${ }^{27}$ No original: “c'est par la mise en commun d'un seul et même ensemble de discours que des individus, aussi nombreux qu'on veut les imaginer, définissent leur appartenance réciproque. En apparence, la seule condition requise est la reconnaissance des mêmes vérités et l'acceptation d'une certaine règle - plus ou moins souple - de conformité avec les discours validés".
} 


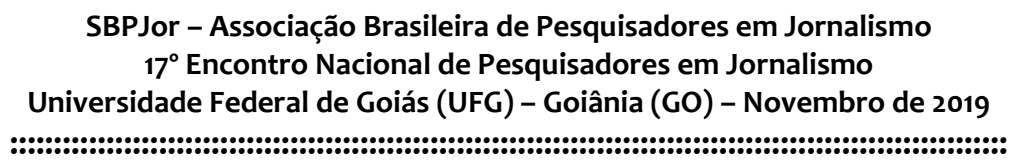

o que não exclui, evidentemente, a pressuposição de que há, no que então se diz, validades mútuas em relação a bens sensíveis aos quais podemos aspirar. A esta racionalidade - que não é outra coisa senão um tipo singular de intuição ${ }^{28}-$, junta-se uma percepção; senso de comunidade e retidão, portanto, o qual ao fim opera nos liames discursivos da episteme de uma época. Como tal, inclusive, circunscreve-se em linguagem distintiva; medium a processos de abertura às realidades alheias.

Há de se considerar, todavia, o caráter sistêmico do jornalismo. Enquanto instituição - com lógicas produtivas diversas e [re]combinações deontológicas próprias -, foge-lhe por vezes a característica de configurar-se como um meio de comunicação, isto é, quando através de si deixa fluir as enunciações sociais. Não se trata de transmiti-las simplesmente, mas, pelo ato mesmo de dar-lhes substância visível, situa-las em relação às expressões dos sujeitos que se engajam na construção desse sistema de narrativa. Daí concluir que, para constituir-se em uma dimensão comunicacional, o aparato jornalístico deve ao fim

falar em silêncio. Esse paradoxo é apenas aparente. Por silenciamento não se quer dizer fazer silêncio num sentido literal e sim silenciar-se para conceder a atuação própria simplesmente como "médium". O ato de "dar lugar" ou "deixar falar o outro" é uma condição especificamente comunicacional, nesse sentido (SIGNATES, 2018, p. 33),

cabendo ao jornalista, no espaço das regras e dinâmicas institucionalizadas, a custosa tarefa de importar-se com o Outro; ver-se presente na forma de ausência - silêncio que, por operar nos jeitos do afeto (não menos sistemático ou mais racional), faz-lhe ver o ponto donde se entrecruzam as sensibilidades postas em diálogo.

Do silenciar-se, portanto, emergem condições de possibilidade à relação de alteridade da enunciação - mesmo quando negativa ou desalentadora, contanto que aberta às soluções sociais; às esperanças num horizonte singular de justiça. Tornam-se os discursos a matéria que sustenta atos ativos e responsivos (por isso intersubjetivos), à medida que a positividade ${ }^{29}$ tecida em enunciados pressupõe de saída a constituição do $e u$

\footnotetext{
${ }^{28}$ Isto é, "uma percepção clara e imediata" (MARCONDES FILHO, 2013, p. 20) do mundo circundante, com tudo o que é aí admitido: experiências, sensações, saberes.

${ }^{29}$ Vista aqui, afinal, não como trajeto do que é essencialmente "bom" na enunciação, mas o que é justo por ser bem comum; sinal de esperança às vistas de silêncios comunicativos.
} 
SBPJor - Associação Brasileira de Pesquisadores em Jornalismo

$17^{\circ}$ Encontro Nacional de Pesquisadores em Jornalismo

Universidade Federal de Goiás (UFG) - Goiânia (GO) - Novembro de 2019

pelo reconhecimento do outro. Não se trata, todavia, de inferir que há na ação hermenêutica do jornalismo uma dimensão ontológica, mas sim que, no abrir-se aos mistérios do Outro (o qual é então primado às falas sociais), instituem-se sujeitos em elos discursivos. Sendo assim,

o tu [...] é quem constitui o eu. O tu me precede. A comunicação é isso e apenas isso: a capacidade de romper a redoma de nós mesmos, o círculo fechado de nossa autossuficiência, e buscar o outro, reconhecer sua alteridade, sua especificidade, sua diferença em relação a mim, sua estranheza (MARCONDES FILHO, 2013, p. 36),

para então sem branduras acolhê-lo; partilhar destinos ao admitirmos sua importância. Rompe-se como tal a autonomia do sujeito na continuidade discursiva, localizando o Outro no ato de ajeitar em coerências ternas (e responsáveis) os diálogos de seu tempo. Tensionam-se, afinal, duas operações enunciativas: a da disposição instrumental quando o jornalismo intenta cruzar as fronteiras dos silêncios que lhe permitem comunicar, e a da sensibilidade quando, ao calar-se por escândalos, faz ver o sem-número de vozes que se lhe atravessam.

A positividade não é tendência estrita ao exercício jornalístico, evidentemente, mas é pretexto à construção de solidariedades explícitas no plano da cidadania. Como palavra posta em história, inclusive, seu projeto é redutor - pois em véu esconde outros discursos -, sendo então urgente à enunciação o compromisso ético de situar a alteridade em relação às vivências sociais.

\section{ALGUMAS CONSIDERAÇÕES}

Perscrutamos neste ensaio a mudança de uma episteme - esta que, de modo geral, é resposta a novos acontecimentos no interior do próprio discurso (ROUANET, 1996, p. 109) ${ }^{30}$. Também tratamos da busca de um sentido ético à comunicação, articulando-a a uma base existencial de vinculação humana pressuposta na enunciação jorna-

${ }^{30}$ Cf. _ S. P. A gramática do homicídio. In: FOUCAULT, M., et al. O homem e o discurso: a arqueologia de Michel Foucault. 2. ed. Rio de Janeiro: Tempo Brasileiro, v. 3, 1996. Cap. 5, p. 91-139. 


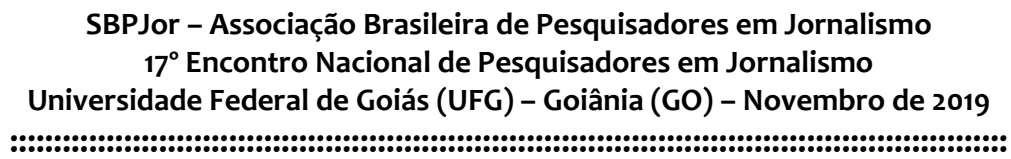

lística. Situamos em trajeto singular a questão da enunciação positiva, vendo-a afinal como uma pretensão de validade às experiências de afetividade [com]partilhadas quando o jornalismo "se faz silêncio" para acolher em tessitura discursiva as realidades do Outro. Eis porque a noção de cidadania aqui exposta carece sobremaneira dos processos comunicacionais de troca e circulação simbólica de sentidos.

Assumimos - e sustentamos como ideal - o pressuposto de que comunicar é agir com fins ao encontro de humanidades, o que, à construção das narrativas sociais do jornalismo, solicita-nos bem mais que intercâmbios informacionais, mas "esforços com vista à partilha de propósitos" (SILVA, 2016, p. 41). É nesse ponto que a enunciação de uma época se vê às voltas duma dimensão insular, porque há, de parte a parte, horizontes ao alcance. $\mathrm{O}$ horizonte do exercício jornalístico é, pois, a experiência de alteridade firmada no ato mesmo de pôr em jeitos menos bravios as conversas que [re]arranjam a realidade.

Quando a violência e o desamparo se tornam referência àquilo que é posto em trajetos sócio-históricos, cabe então ao jornalismo reaver seu projeto de humanidade; cruzar ao fim as fronteiras pouco porosas da notícia para fazer ver em seu discurso os princípios que atendem às demandas da cidadania e que servem como estratégia sensível de mobilização social. Eis como, em vez da desolação imanente de um acontecimento ou outro, trará à luz esperança; assegurará "consolo e carinho" (CORTINA, 2005, p. 205) para daí tecer uma raiz normativa donde emerja o bem comum.

\section{REFERÊNCIAS}

BRAGA, J. L. Comunicação, disciplina indiciária. Matrizes, São Paulo, n. 2, p. 73-88, Abril 2008.

, J. L. Constituição do Campo da Comunicação. Verso e Reverso, São Leopoldo, RS, p. 62-77, Jan/abr 2011.

, J. L. O que é comunicação? Líbero, São Paulo, v. 19, n. 38, p. 15-20, jul./dez. 2016.

CORREIA, J. C. Novos jornalismos e a vida cívica: limites e possibilidades do jornalismo deliberativo. In: J. C. Cidadania digital. Universidade da Beira Interior: [s.n.], 2010. p. 71-100. 


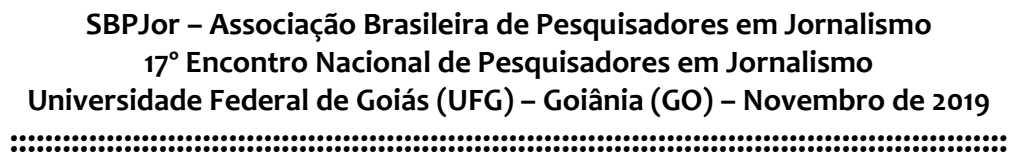

CORTINA, A. Cidadãos do mundo: para uma teoria da cidadania. Tradução de Silvana Cobucci Leite. São Paulo: Edições Loyola, 2005.

FOUCAULT, M. L'ordre du discours. Edition basée sur le texte proposé par l'édition CDROM, Le Foucault Électronique. ed. Paris: Éditions Gallimard, 2001. 103 p.

M. et al. O homem e o discurso: a arqueologia de Michel Foucault. 2. ed. Rio de Janeiro: Tempo Brasileiro, 1996.

GAUTHIER, G. Le journalisme de communication : expression de conviction et moralisme. Les Cahiers du journalisme, Québec, Automne 2010. 254-273.

GOMES, W.; MAIA, R. C. M. Comunicação e democracia: problemas e perspectivas. São Paulo: Paulus, 2008.

HABERMAS, J. O discurso filosófico da modernidade. Tradução de Ana Maria Bernardo [et al.]. 2. ed. Lisboa: Publicações Dom Quixote, 1998.

, J. La inclusión del otro: estudios de teoría política. Barcelona: Paidós, 1999.

, J. Teoria do agir comunicativo: racionalidade da ação e racionalização social. 1. ed. São Paulo: Editora WMF Martins Fontes, v. 1, 2012.

MARCONDES FILHO, C. Nova teoria da comunicação, v.1: o rosto e a máquina: o fenômeno da comunicação visto pelos ângulos humano, medial e tecnológico. 1. ed. São Paulo: Paulus, 2013.

MORAES, Â. T. D. A positividade como valor-notícia: análise discursiva de webjornais orientados à "boa notícia". XXXVII Congresso Brasileiro de Ciências da Comunicação, Foz do Iguaçu, PR, 2-5 set. 2014. 12.

SIGNATES, L. Epistemologia da Comunicação na Democracia: a centralidade do conceito de comunicação na análise dos processos políticos. Novos Olhares, São Paulo, v. 1, n. 1, p. 7-18, 2012a.

L. Epistemologia e comunicabilidade: as crises das ciências, ante a perspectiva da centralidade do conceito de comunicação. Comunicação \& Informação, Goiânia, v. 15, n. 2, p. 133-148, jul./dez. 2012b.

, L. A comunicação, entre o dogma e a conversão: o especificamente comunicacional na religiosidade contemporânea. Estudos de Religião, v. 32, set/dez. 2018. 27-49.

, L.; MORAES, Â. Cidadania comunicacional: teoria, epistemologia e pesquisa. Goiânia: Gráfica UFG, 2016.

SILVA, G.; SILVA, M. P. D.; FERNANDES, M. L. Critérios de noticiabilidade: problemas conceituais e aplicações. Florianópolis: Insular, 2014.

SODRÉ, M. As estratégias sensíveis. Petrópolis: Vozes, 2006. 
SBPJor - Associação Brasileira de Pesquisadores em Jornalismo

$17^{\circ}$ Encontro Nacional de Pesquisadores em Jornalismo

Universidade Federal de Goiás (UFG) - Goiânia (GO) - Novembro de 2019

::::::::::::::::::::::::::::::::::::::::::::::::::::::::::::::::::::::::::::::::::::::::::::::::::::::::::::::::::::::::::

2014.

M. A ciência do comum: notas para o método comunicacional. Petrópolis: Vozes,

VAN DIJK, T. A. Discurso e poder. Tradução de Judith Hoffnagel [et. al]. São Paulo:

Contexto, 2008.

WOLTON, D. Penser la communication. Paris: Flammarion, 1997

$\overline{2006 .}$

D. É preciso salvar a comunicação. Tradução de Vanise Dresch. São Paulo: Paulus, 